\title{
LA PUBLICIDAD EN REVISTAS DE ENFERMERÍA ESPAÑOLAS II
}

\section{(TABLAS DEL ARTÍCULO)}

IRENE GARCÍA HERNÁNDEZ *, ALBERTO GÁLVEZ TORO**,

* Diplomada en Enfermería, Hospital Son Dureta, Palma de Mallorca, España.

** Diplomado en Enfermería y Fisioterápia, Esp. Obstetricia y Ginacología. Profesor Ayudante

EUE, Universidad de Jaén, España.

La información contenida en este artículo se enmarca dentro de la línea de trabajo sobre producción científica vinculada a los proyectos 010/98 de la Fundación Index y Grupo Enfermería CTS 464.

\section{Tabla 1}

\section{INSERCIONES PUBLICITARIAS Y OCUPACIÓN EN LAS REVISTAS DE ENFERMERÍA}

\begin{tabular}{|l|c|c|c|c|c|}
\hline \multicolumn{1}{|c|}{ Revista } & $\begin{array}{c}\text { Números } \\
\text { revisados } \\
\text { por } \\
\text { volumen }\end{array}$ & $\begin{array}{c}\text { Número de } \\
\text { páginas }\end{array}$ & $\begin{array}{c}\text { Número de } \\
\text { inserciones } \\
\text { al año }\end{array}$ & $\begin{array}{c}\text { Número } \\
\text { páginas que } \\
\text { ocupan las } \\
\text { inserciones }\end{array}$ & $\begin{array}{c}\text { Porcentaje de } \\
\text { ocupación } \\
\text { publicitaria por } \\
\text { revista y año }\end{array}$ \\
\hline AEEU & 4 & 336 & 95 & 78,58 & 23,40 \\
\hline $\begin{array}{l}\text { Enfermería } \\
\text { Científica }\end{array}$ & 6 & 520 & 40 & 37 & 7,11 \\
\hline Enfermería Clínica & 6 & 332 & 35 & 36 & 10,84 \\
\hline Enfermería Integral & 4 & 358 & 79 & 51,75 & 14,45 \\
\hline $\begin{array}{l}\text { Enfermería } \\
\text { Intensiva }\end{array}$ & 4 & 198 & 21 & 20 & 10,07 \\
\hline $\begin{array}{l}\text { Enfermería } \\
\text { Radiologica }\end{array}$ & 4 & 122 & 29 & 24,98 & 20,48 \\
\hline $\begin{array}{l}\text { Index de } \\
\text { Enfermería }\end{array}$ & 4 & 272 & 62 & 46,34 & 17,04 \\
\hline Rol de Enfermería & 12 & $\mathbf{8 8 1}$ & 288 & 246 & 27,92 \\
\hline Totales & $\mathbf{4 4}$ & $\mathbf{3 0 1 9}$ pgs & 649 & $\mathbf{5 4 0 , 6 5}$ pgs & $\mathbf{1 7 , 9 0}$ \\
\hline
\end{tabular}




\section{Tabla 2}

\section{TIPO DE PUBLICIDAD}

\begin{tabular}{|c|c|c|c|c|c|}
\hline Revista & $\begin{array}{c}\text { Total } \\
\text { inserciones } \\
\text { año }\end{array}$ & $\begin{array}{c}\text { Productos } \\
\text { farmacéuticos } \\
\text { y clínicos }(\%)\end{array}$ & $\begin{array}{l}\text { Actividades } \\
\text { cientificas (\%) }\end{array}$ & $\begin{array}{l}\text { Autopublicida } \\
\text { d (\%) }\end{array}$ & Otros (\%) \\
\hline AEEU & 95 & $\begin{array}{c}24 \\
22,26 \%\end{array}$ & $\begin{array}{c}51 \\
53,68 \%\end{array}$ & $\begin{array}{c}10 \\
10,53 \%\end{array}$ & $\begin{array}{c}10 \\
10,53 \%\end{array}$ \\
\hline $\begin{array}{l}\text { Enfermería } \\
\text { Científica }\end{array}$ & 40 & $\begin{array}{c}2 \\
5 \%\end{array}$ & $\begin{array}{c}8 \\
20 \%\end{array}$ & $\begin{array}{c}30 \\
75 \%\end{array}$ & - \\
\hline $\begin{array}{l}\text { Enfermería } \\
\text { Clínica }\end{array}$ & 35 & $\begin{array}{c}14 \\
40 \%\end{array}$ & $\begin{array}{c}4 \\
11,43 \%\end{array}$ & $\begin{array}{c}12 \\
34,29 \%\end{array}$ & $\begin{array}{c}5 \\
14,28 \%\end{array}$ \\
\hline $\begin{array}{l}\text { Enfermería } \\
\text { Integral }\end{array}$ & 79 & $\begin{array}{c}4 \\
5,06 \%\end{array}$ & $\begin{array}{c}26 \\
32,91 \%\end{array}$ & $\begin{array}{c}11 \\
13,92 \%\end{array}$ & $\begin{array}{c}38 \\
48,10 \%\end{array}$ \\
\hline $\begin{array}{l}\text { Enfermería } \\
\text { Intensiva }\end{array}$ & 21 & $\begin{array}{c}4 \\
19,05 \% \\
\end{array}$ & $\begin{array}{c}7 \\
33,33 \% \\
\end{array}$ & $\begin{array}{c}7 \\
33,33 \% \\
\end{array}$ & $\begin{array}{c}3 \\
14,28 \% \\
\end{array}$ \\
\hline $\begin{array}{l}\text { Enfermería } \\
\text { Radiológica }\end{array}$ & 29 & $\begin{array}{c}19 \\
65,52 \%\end{array}$ & $\begin{array}{c}5 \\
17,24 \%\end{array}$ & $\begin{array}{c}4 \\
13,79 \%\end{array}$ & $\begin{array}{c}1 \\
3,45 \%\end{array}$ \\
\hline $\begin{array}{l}\text { Index } \\
\text { Enfermería }\end{array}$ & 62 & $\begin{array}{c}12 \\
19,35 \%\end{array}$ & $\begin{array}{c}4 \\
6,45 \%\end{array}$ & $\begin{array}{c}32 \\
51,62 \%\end{array}$ & $\begin{array}{c}14 \\
22,58 \%\end{array}$ \\
\hline $\begin{array}{l}\text { Rol de } \\
\text { Enfermería }\end{array}$ & 288 & $\begin{array}{c}167 \\
57,98 \% \\
\end{array}$ & $\begin{array}{c}49 \\
17,02 \% \\
\end{array}$ & $\begin{array}{c}62 \\
21,53 \% \\
\end{array}$ & $\begin{array}{c}10 \\
3,47 \% \\
\end{array}$ \\
\hline $\begin{array}{l}\text { Total } \\
\text { Inserciones }\end{array}$ & 649 & 246 & 154 & 168 & 81 \\
\hline
\end{tabular}

\section{Tabla 3}

\section{CONTAMINACIÓN PUBLICITARIA: INSERCIONES DENTRO DEL CONTENIDO CIENTÍFICO}

\begin{tabular}{|l|c|c|c|c|c|}
\hline \multicolumn{1}{|c|}{ Revista } & $\begin{array}{c}\text { Total } \\
\text { inserciones } \\
\text { al año }\end{array}$ & $\begin{array}{c}\text { Inserciones en la } \\
\text { parte cientifica }\end{array}$ & $\%$ & $\begin{array}{c}\text { Inserciones } \\
\text { relacionadas con } \\
\text { contenido }\end{array}$ & $\%$ \\
\hline AEEU & 95 & 47 & 49,47 & - & - \\
\hline Enfermería Científica & 40 & 14 & 35,00 & - & - \\
\hline Enfermería Clínica & 35 & 12 & 34,29 & - & - \\
\hline Enfermería Integral & 79 & - & - & - & - \\
\hline Enfermería Intensiva & 21 & - & - & - & - \\
\hline Enfermería & 29 & 8 & 27,59 & 2 & 6,90 \\
\hline Radiológica & 62 & 30 & 48,39 & 1 & 1,61 \\
\hline Index de Enfermería & 288 & 193 & 67,01 & 16 & 5,55 \\
\hline Rol de Enfermería & 649 & 231 & 35,59 & 19 & 2,93 \\
\hline Totales & & & & \\
\hline
\end{tabular}




\section{Gráfico 1 \\ Porcentaje de ocupación publicitaria por revista}

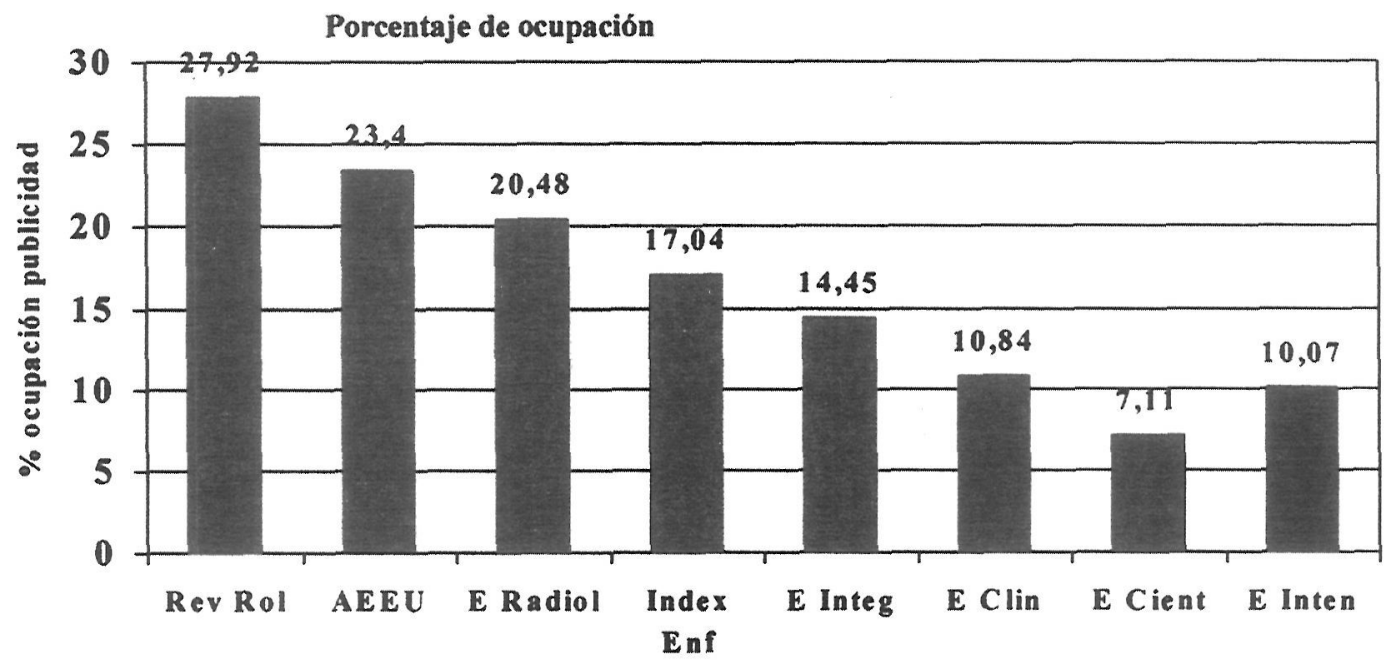

Revistas fuente 